\title{
Design, Optimization, and Evaluation of Lurasidone Hydrochloride Nanocrystals
}

\author{
Sunny Shah, ${ }^{1,2}$ Bhavin Parmar, ${ }^{1}$ Moinuddin Soniwala, ${ }^{1}$ and Jayant Chavda ${ }^{1}$
}

Received 1 August 2015; accepted 6 November 2015; published online 19 November 2015

\begin{abstract}
The present investigation was carried out to design, optimize, and evaluate lurasidone hydrochloride nanocrystals for improving its solubility and dissolution characteristics. Nanocrystals were prepared by media milling technique using zirconium oxide beads with $0.1 \mathrm{~mm}$ diameter. Various stabilizers, viz. poloxamer 188, PVP K30, SLS, HPMC E15, and PVP S 630 D, were evaluated to stabilize the nanocrystals. The Pareto chart obtained through Plackett-Burman screening design revealed that HPMC E 15 showed the highest standardized effect $(p$ value $<0.05)$ on percent dissolution efficiency at $2 \mathrm{~min}$. In subsequent studies, a $3^{2}$ factorial design was employed to quantify the effect of two independent variables, namely amount of stabilizer and milling time on predetermined response variables mean particle size, saturation solubility, and percent dissolution efficiency at $2 \mathrm{~min}$. Statistical analysis of the factorial design revealed that all predetermined response variables were significantly dependent ( $p$ value $<0.05$ ) on the independent variables. The observed response of the optimized batch prepared as per the desirability function was in close agreement with predicted response, and mathematical model generated was validated. The optimized batch was lyophilized, and X-ray powder diffraction studies indicated that there was no substantial change in crystallinity of the drug. The optimized formulation showed mean particle size of $228 \mathrm{~nm}$ and released almost all the drug within first $5 \mathrm{~min}$. Since the crystallinity of the drug is maintained, improvement in saturation solubility and dissolution efficiency could be attributed to decrease in mean particle size of the drug.
\end{abstract}

KEYWORDS: $3^{2}$ full factorial design; dissolution efficiency; lurasidone hydrochloride; media milling; nanocrystals; plackett-burman screening design.

\section{INTRODUCTION}

Bipolar depression is a serious, chronic psychiatric disorder with a lifetime prevalence of approximately $1 \%$ worldwide and major adverse consequences such as impairments in cognition, social functioning, and work capacity $(1,2)$. Antipsychotic drugs are treatment of choice for both acute and longterm management of bipolar depression; the most distressing clinical signs and symptoms are managed with the long-term use of antipsychotic medication along with effective psychosocial interventions (3).

Lurasidone hydrochloride (3aR,4S,7R,7aS)-2-\{(1R,2R)2-[4-(1,2-benzisothiazol-3-yl) piperazin-1-ylmethyl] cyclohexylmethyl hexahydro-4,7-methano-2H isoindole-1,3dione hydrochloride (Fig. 1) is an atypical antipsychotic and mediates its pharmacological action by blocking central dopamine D2 neuroreceptors (4,5). Lurasidone hydrochloride has been approved by the US Food and Drug administration for treatment of bipolar depression alone or in combination with lithium in adults (6). It is currently marketed under the trade name of Latuda ${ }^{\mathrm{TM}}$ and is a drug of choice since it causes minimal effects on body weight, has low potential of sedation,

\footnotetext{
$\overline{{ }^{1} \text { Department of Pharmaceutics, B. K. Mody Government Pharmacy }}$ College, Government Polytechnic Campus, Rajkot, India.

${ }^{2}$ To whom correspondence should be addressed. (e-mail: sunnyrshah@yahoo.com)
}

and does not cause significant changes across metabolic parameters (7). The innovator concludes that lurasidone absorption is influenced by food consumption and when administered with food the absorption of lurasidone showed a twofold increase; the maximum concentration $\left(C_{\max }\right)$ also increased by threefold. The $T_{\max }$ is shown to increase by $0.5-$ $1.5 \mathrm{~h}$ with food. Considering the significant food effect on the bioavailability of lurasidone, it is recommended to be administered once daily with at least $350 \mathrm{cal}$ of food (Latuda Prescribing Information accessed from www.latuda.com) (8).

Lurasidone hydrochloride has very low aqueous solubility (water $0.224 \mathrm{mg} / \mathrm{ml}$ ) with the $\mathrm{pKa}$ value of 7.6 and $\operatorname{LogP}$ value of 5.6 in octanol/water (Australian Public Assessment Report for lurasidone hydrochloride, accessed from www.tga.gov.au) (9). This low aqueous solubility could be responsible for low bioavailability which is estimated to be about 9 to $19 \%$. Moreover, as discussed earlier, lurasidone hydrochloride has to be given with food for efficient absorption. However, for poorly soluble drugs, the presence of food interferes in the dissolution and uniform absorption of drugs (10). Kesisoglou and co-authors have classically reviewed the food interaction with dissolution of poorly soluble drugs (11). In this perspective, it is evident that the presence of food may interfere in the dissolution and uniform absorption of lurasidone hydrochloride from the gastrointestinal tract. Hence, improving the solubility and dissolution characteristics of lurasidone hydrochloride might allow 


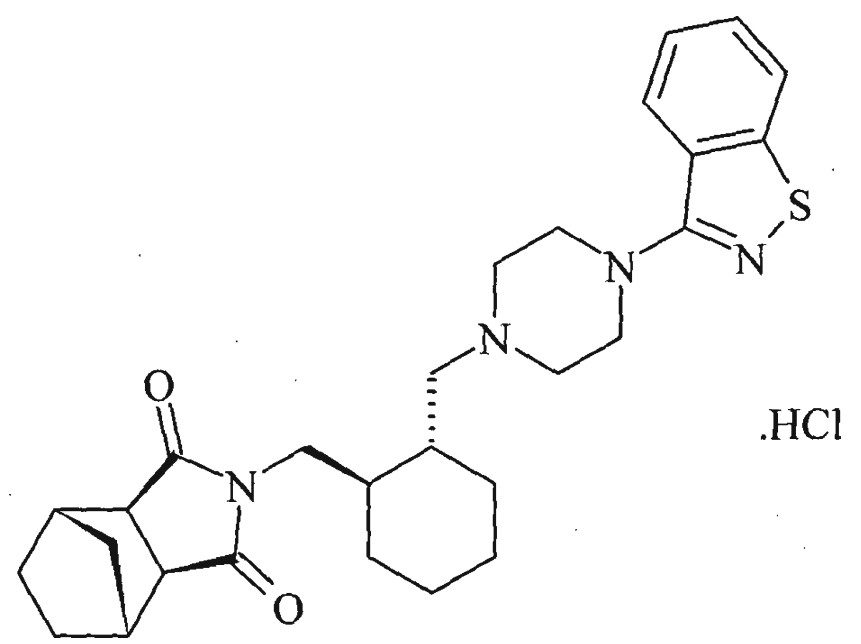

Fig. 1. Lurasidone hydrochloride

uniform absorption of the drug from the gastrointestinal tract, which may also enhance the bioavailability of the drug.

Discrete research has been reported for dissolution enhancement of lurasidone hydrochloride. The patent applications PCT/IN2013/000693 (12) and PCT/IL2011/050009 (13) describes preparation of amorphous lurasidone hydrochloride and concludes that the amorphous form of lurasidone hydrochloride shows higher bioavailability as compared to the existing crystalline form of lurasidone hydrochloride. Madan and coworkers prepared fast-dissolving tablets of solid dispersion of lurasidone hydrochloride to improve the dissolution of lurasidone hydrochloride (14). Qian and co-workers improved dissolution of lurasidone hydrochloride by preparing coamorphous lurasidone hydrochloride with saccharin and concluded that coamorphous lurasidone hydrochloride greatly improved the solubility with $\mathrm{pH}$-independent solubility behavior as compared to amorphous lurasidone (15). However, a systematic approach for development of nanocrystals for the dissolution enhancement of lurasidone hydrochloride was still lacking. Nanocrystal formulations of poorly soluble drugs such as fenofibrate (TriCor $\AA$, Abbott), sirolimus (Rapamune $\AA$, Wyeth), and megestrol (Megace ES $\AA$, PAR Pharmaceuticals) have been developed for improving their dissolution and in turn improve their bioavailability (16). Nanocrystals as a formulation approach have been widely employed for improving the solubility and dissolution characteristics of poorly soluble drugs (17). Extensive review of literature is available discussing the advantages, development, and evaluation of drug nanocrystals $(18,19)$ over conventional methods of dissolution enhancement such as solid dispersions, amorphization of drug, and co solvency. In brief, drug nanocrystals are the choice of formulation for improving solubility and dissolution of poorly soluble drugs. They are $100 \%$ drug particle without any matrix material and stabilized by steric or ionic stabilizers (20). In light of this, the present investigation was carried out to develop, optimize, and evaluate lurasidone hydrochloride nanocrystals to improve the saturation solubility and dissolution efficiency of lurasidone hydrochloride. The following objectives were decided to be achieved:

1. To prepare drug nanocrystals with mean particle size less than $250 \mathrm{~nm}$

2. To improve percent dissolution efficiency at $2 \mathrm{~min}$ $\left(\% \mathrm{DE}_{2 \mathrm{~min}}\right)$

3. To achieve more than $85 \%$ drug release within the first $5 \mathrm{~min}$

\section{MATERIALS}

Lurasidone hydrochloride (pure) was received as a gift sample from Torrent Pharmaceuticals Ahmedabad Gujarat India. Poloxamer 188 (PX), a tri co block polymer of polyethylene oxide and polypropylene oxide, was received as a gift sample from Cadila Pharmaceuticals Limited, Ahmedabad, Gujarat, India. Polyvinylpyrrolidone S 630 D (PD), a copolymer of polyvinyl pyrrolidone and polyvinyl acetate, was

Table I. Layout of Plackett-Burman Screening Design (Average \pm Standard Deviation, $n=3$ )

\begin{tabular}{|c|c|c|c|c|c|c|}
\hline $\mathrm{PX}$ & PVP K30 & SLS & HPMC E 15 & PD & $\% \mathrm{DE}_{2 \min }$ & Saturation solubility \\
\hline+1 & +1 & -1 & +1 & -1 & $22.58 \pm 1.25$ & $368.25 \pm 8.52$ \\
\hline+1 & +1 & +1 & -1 & +1 & $12.09 \pm 1.36$ & $276.13 \pm 5.69$ \\
\hline+1 & +1 & +1 & +1 & -1 & $27.48 \pm 2.24$ & $428.36 \pm 9.25$ \\
\hline-1 & +1 & +1 & +1 & +1 & $23.79 \pm 0.52$ & $387.4 \pm 5.25$ \\
\hline+1 & -1 & +1 & +1 & +1 & $26.00 \pm 1.58$ & $415.20 \pm 4.89$ \\
\hline-1 & +1 & -1 & +1 & +1 & $21.41 \pm 2.33$ & $347.14 \pm 8.25$ \\
\hline+1 & -1 & +1 & -1 & +1 & $14.90 \pm 3.62$ & $296.06 \pm 9.25$ \\
\hline-1 & -1 & -1 & -1 & -1 & $18.56 \pm 3.33$ & $325.5 \pm 8.25$ \\
\hline
\end{tabular}




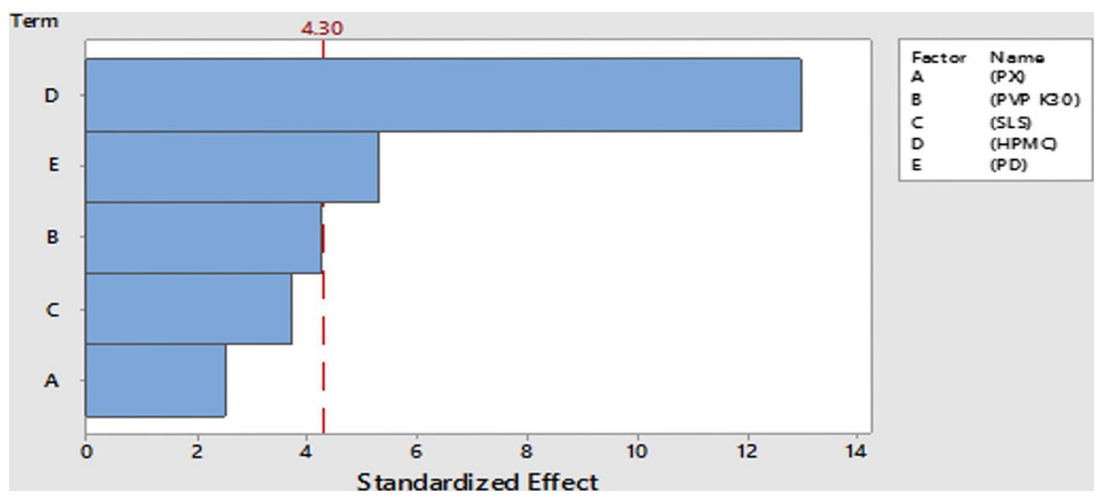

Fig. 2. Pareto chart for standardized effect on $\% \mathrm{DE}$

received as a gift sample from International Specialty Products, Singapore. PVP K 30 was received as a gift sample from ACS chemicals, Ahmadabad, Gujarat, India. HPMC E 15 was received as a gift sample from Loba chemie, Mumbai, Maharashtra, India. Sodium lauryl sulfate (SLS) AR grade was received as a gift sample from Finar limited, Ahmedabad, Gujarat, India. Double-distilled water was used throughout the study.

\section{METHODS}

\section{Preparation of Drug Nanocrystals}

Lurasidone hydrochloride nanocrystals were prepared using media milling technique (21). Briefly, the unmilled drug and formulation vehicle were mixed in a vial. The zirconium oxide beads ( $0.1 \mathrm{~mm}$ diameter) were then added to the vial to achieve a predetermined percentage of 1:1 w/w suspension-tobead ratio. A magnetic stir bar was added and the vial was placed on a magnetic stirrer (Remi Instruments Pvt. Ltd.). The milling was done for a predetermined period of time (12-24 h) and speed (400-800 rpm), the milled suspensions were then collected using transfer pipettes, and beads were rinsed with formulation vehicle, each time the final concentration of lurasidone hydrochloride in suspension was kept at $5 \mathrm{mg} / \mathrm{ml}$.

\section{Plackett-Burman Screening Design}

A Plackett-Burman screening design was employed to screen the formulation variables having significant effect on dissolution of lurasidone hydrochloride. PlackettBurman designs are screening designs that involve a large number of factors and relatively few runs. They are typically used to identify a few significant factors out of a large set (22). Five assorted stabilizers were evaluated by a total of eight experiments generated from Minitab ${ }^{\circledR} 17.0$ (trial version). $A$ (amount of PX), $B$ (amount of PVP K 30), $C$ (amount of SLS), $D$ (amount of HPMC E 15), and $E$ (amount of $\mathrm{PD}$ ) were selected as independent variables while $\mathrm{Y} 1\left(\% \mathrm{DE}_{2} \mathrm{~min}\right)$ and $\mathrm{Y} 2$ (saturation solubility, $\left.\mu \mathrm{g} / \mathrm{ml}\right)$ were selected as dependent variables.

\section{Factorial Design}

A $3^{2}$ full factorial design was employed to assess and quantify the impact independent variables on dependent variables (21). Based on the preliminary studies, the amounts of HPMC E $15\left(X_{1}\right)$ and milling time $\left(X_{2}\right)$ were selected as independent variables, while mean particle size (Y1), $\% \mathrm{DE}_{2 \min }(\mathrm{Y} 2)$, and saturation solubility $(\mu \mathrm{g} / \mathrm{ml})(\mathrm{Y} 3)$ were selected as dependent variables.

Table II. Layout and Observed Response of $3^{2}$ Full Factorial Design (Average \pm Standard Deviation, $n=3$ )

\begin{tabular}{|c|c|c|c|c|c|c|c|}
\hline \multirow[t]{3}{*}{ Formulation } & \multicolumn{4}{|c|}{ Independent variables } & \multicolumn{3}{|c|}{ Dependent variables } \\
\hline & \multicolumn{2}{|c|}{ Coded value } & \multicolumn{2}{|c|}{ Decoded value } & & & \\
\hline & $\mathrm{X} 1$ & $\mathrm{X} 2$ & $\mathrm{X} 1$ & $\mathrm{X} 2$ & Particle size (nm) & $\% \mathrm{DE}_{2 \min }$ & Saturation solubility $(\mu \mathrm{g} / \mathrm{ml})$ \\
\hline $\mathrm{F} 1$ & -1 & -1 & 7.5 & 12 & $922 \pm 12$ & $37.07 \pm 1.22$ & $505.17 \pm 19.32$ \\
\hline $\mathrm{F} 2$ & 0 & -1 & 32.5 & 12 & $720 \pm 11$ & $40.69 \pm 2.38$ & $591.37 \pm 23.57$ \\
\hline F3 & 1 & -1 & 57.5 & 12 & $751 \pm 14$ & $38.62 \pm 2.35$ & $572.31 \pm 21.87$ \\
\hline $\mathrm{F} 4$ & -1 & 0 & 7.5 & 18 & $554 \pm 10$ & $40.69 \pm 1.69$ & $608.62 \pm 18.23$ \\
\hline F5 & 0 & 0 & 32.5 & 18 & $401 \pm 7$ & $43.62 \pm 0.45$ & $827.58 \pm 41.22$ \\
\hline F6 & 1 & 0 & 57.5 & 18 & $498 \pm 6$ & $41.55 \pm 1.00$ & $768.96 \pm 13.54$ \\
\hline F7 & -1 & 1 & 7.5 & 24 & $330 \pm 8$ & $45.52 \pm 1.94$ & $1158.89 \pm 34.11$ \\
\hline F8 & 0 & 1 & 32.5 & 24 & $226 \pm 9$ & $49.66 \pm 0.21$ & $1334.48 \pm 19.27$ \\
\hline F9 & 1 & 1 & 57.5 & 24 & $292 \pm 6$ & $46.72 \pm 0.87$ & $1256.89 \pm 28.96$ \\
\hline
\end{tabular}




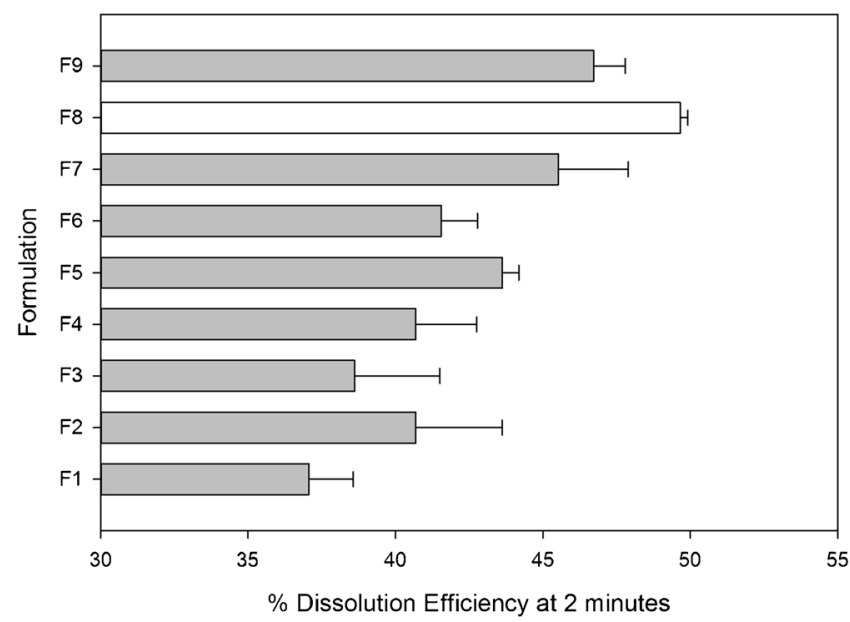

Fig. 3. $\% \mathrm{DE}_{2 \min }$ for $3^{2}$ full factorial design formulations (average \pm standard deviation, $n=3$ )

\section{Evaluation Parameters}

\section{In Vitro Dissolution Studies}

In vitro dissolution studies (Electrolab Dissolution Tester TDT-06P, USP) were carried out in $500 \mathrm{ml}$ Mcllvaine buffer $\mathrm{pH} 3.8$ at $37^{\circ} \mathrm{C}$ at $50 \mathrm{rpm}$ by paddle method (USFDA Guidelines) $(23,24)$. Briefly, $5 \mathrm{ml}$ of nanosuspension formulation was added to the dissolution medium, and sampling was done at 2, 4, 6, 8, 10, 15, 20, 30,45 , and $60 \mathrm{~min}$ interval. The samples were filtered with Whatman filter paper $(0.22 \mu \mathrm{m})$ (21) and assayed spectrophotometrically for the dissolved drug at $234 \mathrm{~nm}$ by the regression equation of standard curve developed in the same media in the linearity range of $5.0-30.0 \mu \mathrm{g} / \mathrm{ml}$. The dissolution medium was replenished with equal amount of buffer at each time interval. The \%DE was calculated using the following equation (25):

$$
\mathrm{oDE}_{T}=\left(\frac{\int_{0}^{T} y_{t} d t}{y_{100} \cdot T}\right) 100 \quad \ldots \quad \ldots \quad \ldots
$$

\section{Determination of Saturation Solubility}

Excess amount of pure lurasidone hydrochloride or different formulations of lurasidone hydrochloride were added to $10 \mathrm{ml}$ of Mcllvaine buffer $\mathrm{pH}$ 3.8. Samples were sonicated briefly for $5 \mathrm{~s}$ using a batch sonicator and stirred in a water bath $\left(37 \pm 0.5^{\circ} \mathrm{C}\right)$ for $48 \mathrm{~h}$. Samples were then centrifuged, filtered, diluted suitably, and analyzed spectrophotometrically as described earlier for determining the saturation solubility of lurasidone hydrochloride.

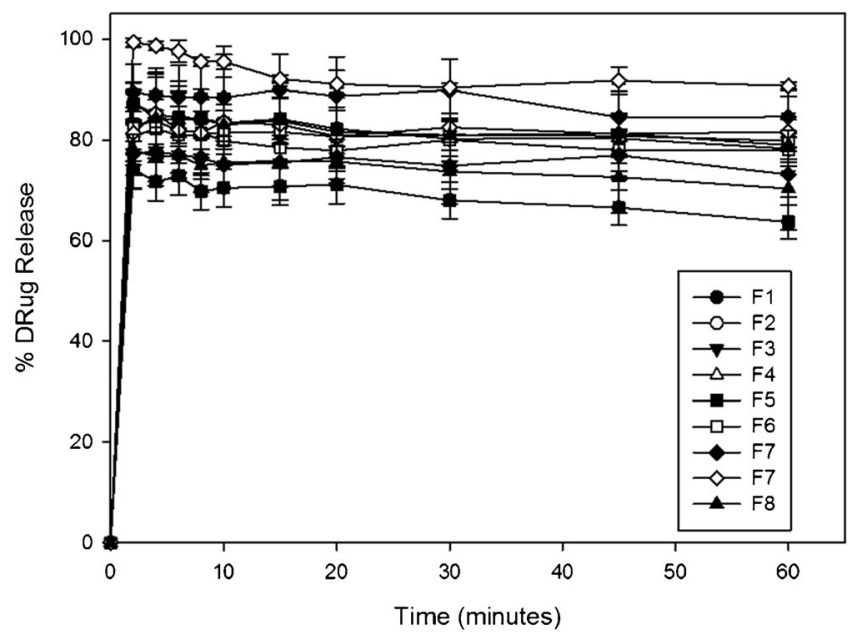

Fig. 4. In vitro drug release of $3^{2}$ full factorial design formulations (average \pm standard deviation, $n=3$ ) 
Table III. Statistical Analysis of $3^{2}$ Full Factorial Design

\begin{tabular}{|c|c|c|c|c|c|c|c|c|c|}
\hline $\begin{array}{l}\text { Observed } \\
\text { Responses }\end{array}$ & & b0 & $\mathrm{X} 1$ & $\mathrm{X} 2$ & $\mathrm{X} 12$ & X11 & $\mathrm{X} 22$ & $F_{\text {calculated }}$ & $R^{2}(\%)$ \\
\hline $\begin{array}{l}\text { Mean particle } \\
\text { size (nm) } \\
\quad(\mathrm{Y} 1)\end{array}$ & $\begin{array}{l}p \text { value } \\
\text { Coefficient }\end{array}$ & $\begin{array}{l}0.000128 \\
411.7778\end{array}$ & $\begin{array}{l}0.014969 \\
-44.1667\end{array}$ & $\begin{array}{l}0.000086 \\
-257.5\end{array}$ & $\begin{array}{l}0.005553 \\
108.8333\end{array}$ & $\begin{array}{l}0.034597 \\
55.83333\end{array}$ & $\begin{array}{l}0.053094 \\
33.25\end{array}$ & 193.52 & 99.84 \\
\hline$\% \mathrm{DE}_{2 \min }(\mathrm{Y} 2)$ & $\begin{array}{l}p \text { value } \\
\text { Coefficient }\end{array}$ & $\begin{array}{l}6.52 \mathrm{E}-07 \\
43.92778\end{array}$ & $\begin{array}{l}0.033042 \\
0.601667\end{array}$ & $\begin{array}{l}0.000117 \\
4.253333\end{array}$ & $\begin{array}{l}0.686032 \\
-0.0875\end{array}$ & $\begin{array}{l}0.001761 \\
-2.96167\end{array}$ & $\begin{array}{l}0.02918 \\
1.093333\end{array}$ & 169.51 & 99.64 \\
\hline $\begin{array}{l}\text { Saturation } \\
\text { Solubility } \\
\text { (Y3) }\end{array}$ & $\begin{array}{l}p \text { value } \\
\text { Coefficient }\end{array}$ & $\begin{array}{l}0.000115 \\
805.7243\end{array}$ & $\begin{array}{l}0.046312 \\
54.24672\end{array}$ & $\begin{array}{l}0.000236 \\
346.9001\end{array}$ & $\begin{array}{l}0.034177 \\
-106.006\end{array}$ & $\begin{array}{l}0.009837 \\
168.1333\end{array}$ & $\begin{array}{l}0.728412 \\
7.714914\end{array}$ & 99.99 & 99.70 \\
\hline
\end{tabular}

\section{Determination of Mean Particle Size and Size Distribution}

Mean particle size of lurasidone hydrochloride nanocrystals was determined using Zetatrac (Microtrac Inc., USA). Suspension samples were directly placed into cuvette and mean particle size and size distribution were measured in triplicate.

\section{Powder X-Ray Diffraction}

The crystallinity of lurasidone hydrochloride and lyophilized formulation were evaluated by powder X-ray diffraction (PXRD) studies. The PXRD spectra of the pure lurasidone hydrochloride and lyophilized lurasidone hydrochloride nanocrystals were recorded using a Rikagu, Philips X Ray Diffractometer, between $10^{\circ}$ and $40^{\circ}$ at $2 \theta$ range.

\section{Statistical Evaluation}

The experimental data obtained were validated by analysis of variance Student's $t$ test or analysis of variance (ANOVA) combined with the $F$ test. The determination coefficient ( $R^{2}$ agreement between the experimental results and predicted values obtained from the model) and the model $F$ value (Fisher variation ratio, the ratio of mean square for regression to mean square for residual) were applied for statistical evaluation.

\section{RESULTS AND DISCUSSION}

\section{Plackett-Burman Screening Design}

Plackett-Burman screening design was applied to screen the various stabilizers having significant effect on $\% \mathrm{DE}$ and saturation solubility. As shown in Table I, five independent variables were selected, viz. PX $(A)$, PVP K $30(B)$, SLS $(C)$, HPMC E15 $(D)$, PD $(E)$, and $\% \mathrm{DE}_{2 \min }$ and saturation solubility selected as a dependent factor. As shown in Fig. 2, the Pareto chart revealed that HPMC E15, PD, and SLS ( $p$ value $<0.05$ ) showed significant effect on $\% \mathrm{DE}_{2 \mathrm{~min}}$. However, HPMC E 15 showed highest standardized effect on both the response variables and was selected as stabilizer in further studies

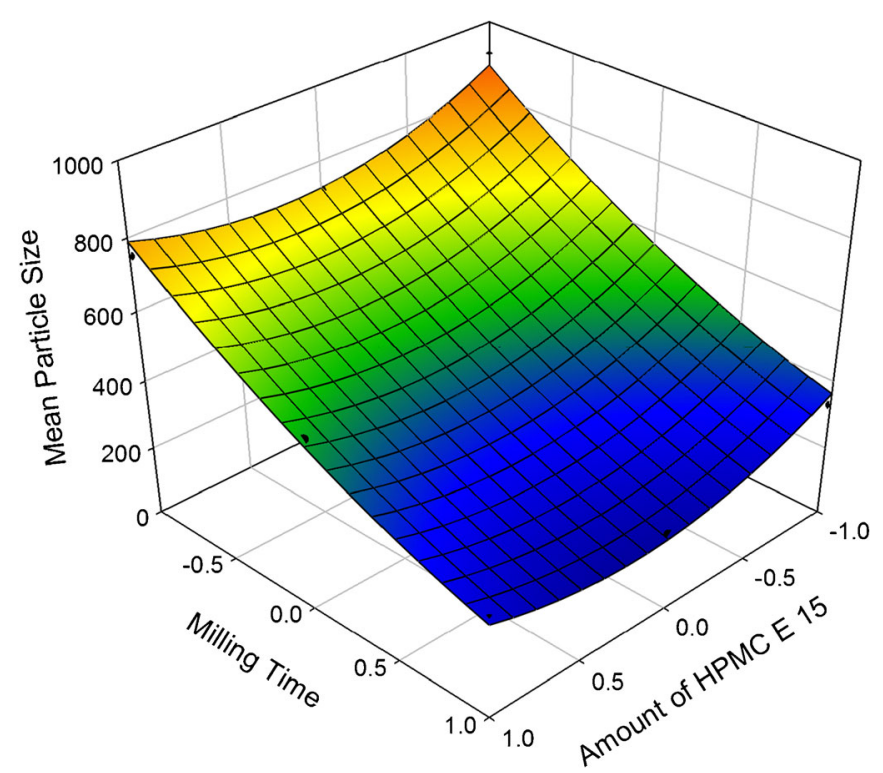

Fig. 5. Response surface plot of effect of amount of stabilizer and milling time on mean particle size 


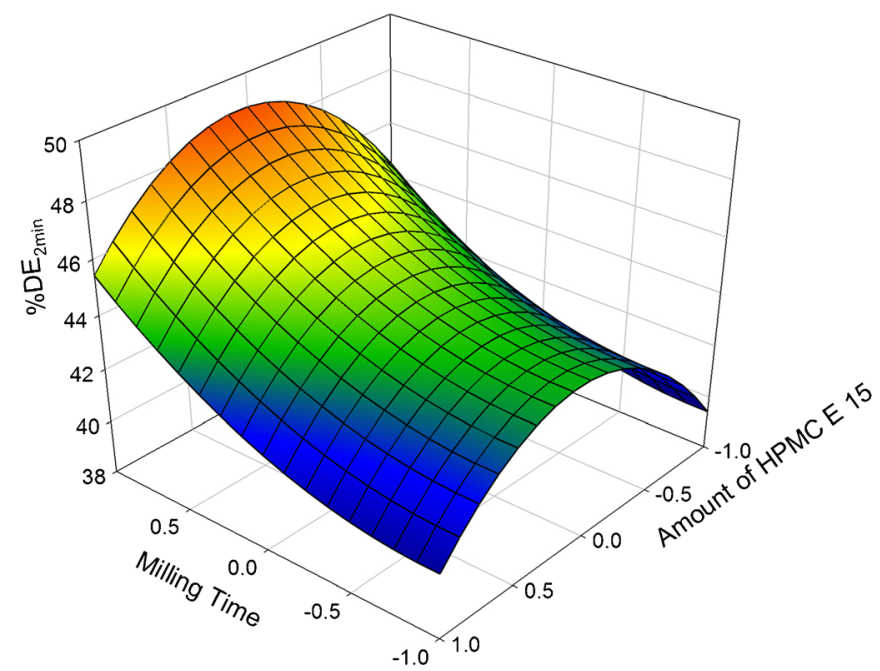

Fig. 6. Response surface plot of effect of amount of stabilizer and milling time on $\% \mathrm{DE}_{2 \min }$
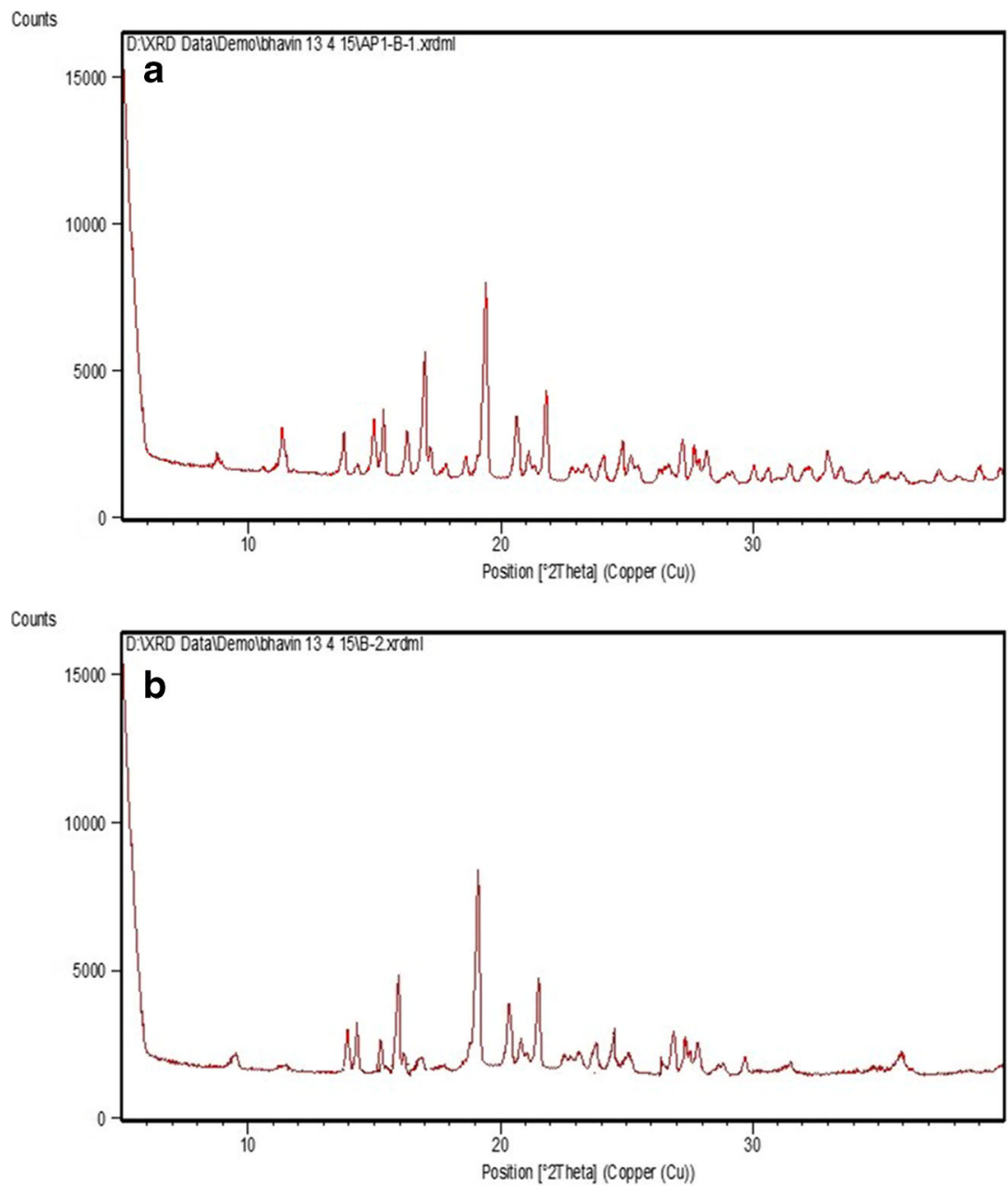

Fig. 7. a XRD spectra of pure lurasidone hydrochloride. $\mathbf{b}$ XRD spectra of optimized batch of lurasidone hydrochloride nanocrystals 


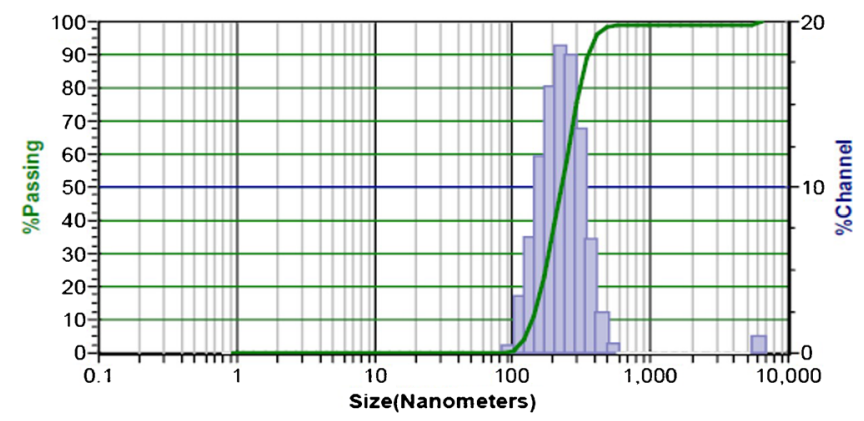

Fig. 8. Particle size distribution of optimized batch of lurasidone hydrochloride nanocrystals

\section{$3^{2}$ Factorial Design}

From the preliminary studies, it was concluded that HPMC E 15 as a formulation variable showed the highest significant effect on \%DE at $2 \mathrm{~min}$ and saturation solubility. Our previous studies suggested that milling time and milling speed also has prominent effect on mean particle size reduction which in turn would have impact on $\% \mathrm{DE}_{2 \min }$ and saturation solubility. Based on the preliminary studies (data not shown), the milling speed at $800 \mathrm{rpm}$ showed optimum particle size reduction and hence was selected for further studies. Further, to study the combined effect of the amount of HPMC E 15 and milling time, a $3^{2}$ full factorial design was employed. Table II reveals the layout of full factorial design while Figs. 3 and 4 depicts $\% \mathrm{DE}_{2 \min }$ and the in vitro dissolution studies of the formulation batches, respectively. A wide variation was seen among the observed response indicating that the independent variables had significant effect on dependent variables. For further statistical analysis, the three responses were individually fitted to the second-order polynomial model and each model was validated by analysis of variance combined with the $F$ test $(26,27)$. As shown in Table III, the independent variables had significant effect $(p$ value $<0.05)$ for all the response variables. All of the regression models yielded a good fit with high determination coefficient and $F$ value. The goodness of fit of the model was confirmed since the $R^{2}$ for all the three responses were larger than 0.9 , indicating that over $90 \%$ of the variation in the response could be explained by the model. The $F$ ratio was found to be far greater than the theoretical value for each regression model, indicating that the regression model is significant with a confidence level of $95 \%$.

\section{Effect of Amount of Stabilizer and Milling Time on Mean Particle Size Reduction}

Response surface plots were generated to graphically represent the effect of amount of stabilizer and milling time on mean particle size reduction. As shown in Fig. 5 at lower level of milling time when amount of polymer was increased from -1 to 0 , the mean particle size decreased from 922 to $720 \mathrm{~nm}$. Further increase in HPMC E 15 from 0 to -1 , there was increase in the mean particle size from 720 to $751 \mathrm{~nm}$. Such an observation could be ascribed to the fact that HPMC E 15 is a steric stabilizer and optimum level of HPMC E 15 is sufficient enough to prevent agglomeration of nanocrystals. When two drug nanocrystals surrounded by an adsorbed HPMC E 15 layer approach each other, it leads to increased osmotic pressure and in turn increases total potential energy and nanocrystals repel each other which could be responsible for prevention of agglomeration (28). Hence, when the amount of HPMC E 15 was increased from -1 to 0 , enough

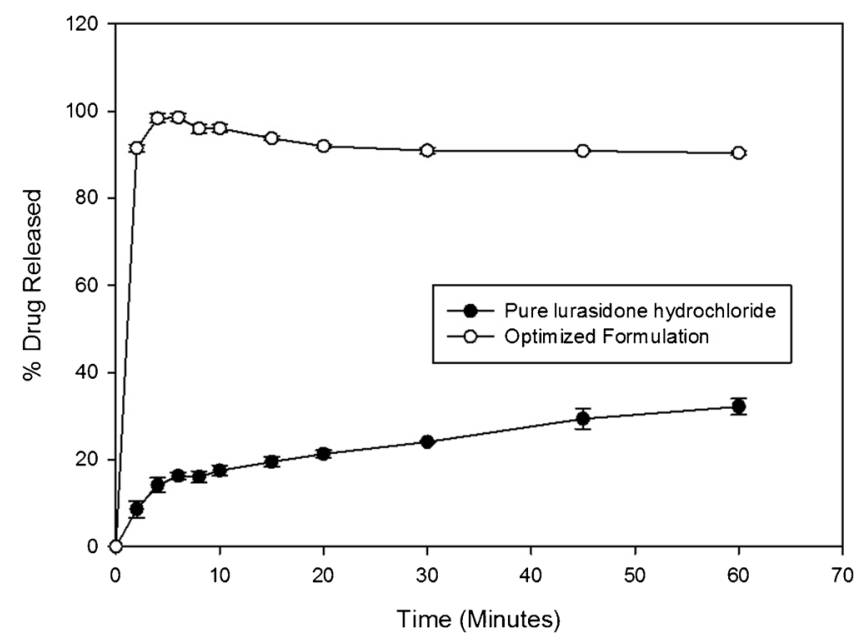

Fig. 9. In vitro drug release comparison of pure lurasidone hydrochloride and optimized lurasidone hydrochloride nanocrystals (average \pm standard deviation, $n=3$ ) 
Table IV. Experimental and Observed Values of Optimized Batch

\begin{tabular}{llll}
\hline Response & Predicted & Observed & $\%$ biased \\
\hline Mean particle size (nm) (Y1) & 226 & 228 & 0.08 \\
$\% E_{2 \min }(\mathrm{Y} 2)$ & 49.65 & 49.31 & 0.60 \\
$\begin{array}{l}\text { Saturation solubility } \\
\quad(\mu \mathrm{g} / \mathrm{ml})(\mathrm{Y} 3)\end{array}$ & 1334 & 1324 & 0.07 \\
\hline
\end{tabular}

HPMC E 15 is present to stabilize the nanocrystals; however, further increase in amount of HPMC E 15 increases the viscosity of the solution which in turn would reduce the efficiency of the milling process and thus, a lesser decrease in mean particle size was seen. Increasing the milling time from -1 to +1 at middle level of stabilizer decreased the particle size from 720 to $226 \mathrm{~nm}$. The decrease in particle size could be attributed to breaking of drug particles due shearing forces generated by milling (21).

\section{Effect of Amount of Stabilizer and Milling Time on \%DE and Saturation Solubility}

As shown in Fig. 6 for all the levels of the amount of stabilizer, there was increase in $\% \mathrm{DE}_{2 \min }$ and saturation solubility when the milling time was increased from -1 to +1 . At the middle level of stabilizer increase in milling time from lower level to higher level, there was increase in $\% \mathrm{DE}_{2 \min }$ from 40.68 to 49.65 and increase in saturation solubility from 591 to $1334 \mu \mathrm{g} / \mathrm{ml}$. The increase in saturation solubility and $\% \mathrm{DE}_{2 \min }$ could be attributed to decrease in particle size with increase in the milling time attributed to Ostwald Freundlich equation (29). As shown in Eq. 2, the Ostwald-Freundlich equation relates the particle size with saturation solubility

$\log _{\frac{C_{S}}{C_{\propto}}}=\frac{2 \sigma V}{2.303 R T \rho r} \ldots \ldots \quad \ldots$

where $C_{S}$ is the saturation solubility, $C_{\propto}$ is the solubility of the solid consisting of unmilled particles, $\sigma$ is the interfacial tension of drug particle, $V$ is the molar volume of the particle, $R$ is the gas constant, $T$ is the absolute temperature, $\rho$ is the density of the solid, and $r$ is the radius of particle. From the equation, it is apparent that the saturation solubility increases with decrease in particle size; however, this effect is more pronounced for particle in the nanometer range. Accordingly, the decrease of particle size of lurasidone hydrochloride to nanometer range increases its saturation solubility and dissolution characteristics.

\section{OPTIMIZATION}

Optimization studies were carried out to prepare lurasidone hydrochloride with set constraints. Based on the equation obtained from factorial design, the desirability function (30,31) was applied using Minitab 17. The constraints set were to minimize response $\mathrm{Y} 1$ and maximize response $\mathrm{Y} 2$ and Y3. An optimum $D$ of 1.000 was obtained at respective levels of X1 (32.5 mg of HPMC E 15) and X2 (24 h.). A final formulation was prepared according to the levels obtained from desirability function. To improve the stability of prepared nanocrystals, the optimized formulation of nanocrystals was lyophilized. Mannitol was used as a cryoprotectant in the ratio of $1: 1$ of the total amount of drug and stabilizer added. Powder X-ray diffraction studies of lyophilized lurasidone hydrochloride and pure lurasidone hydrochloride drug were done to assess the change in crystallinity of the drug. As shown in Fig. 7a, b, it could be seen that almost all the peaks of the pure lurasidone hydrochloride were retained in the lyophilized lurasidone hydrochloride confirming that the crystallinity of the drug was maintained. The optimized formulation was then compared with pure lurasidone hydrochloride. As shown in Fig. 8, the optimized formulation showed mean particle size of $228 \mathrm{~nm}$, and as shown in Fig. 9, the pure drug exhibited $\% \mathrm{DE}_{2 \min }$ of 5 while lurasidone hydrochloride nanocrystals showed $\% \mathrm{DE}_{2 \min }$ of 49.46 and released almost all the drug within the first 5 min. As shown in Table IV, the evaluation parameters confirmed that there was a close agreement between theoretical and practical values of observed responses validating the mathematical model generated. It could be concluded that the crystallinity of the drug was maintained in the optimized formulation and increase in \%DE and saturation solubility could be attributed to decrease in mean particle size to nanometer range.

\section{CONCLUSION}

The dissolution of lurasidone hydrochloride was improved by preparing nanocrystals using media milling technique. The Pareto chart from Plackett Burman screening design revealed that HPMC E15 was having significant effect on saturation solubility and dissolution. $3^{2}$ full factorial design revealed that both the independent variables amount of stabilizer and milling technique significantly affected all the response variables, i.e., mean particle size, $\% \mathrm{DE}_{2 \mathrm{~min}}$, and saturation solubility. The optimized formulation showed significant improvement in dissolution efficiency as compared to pure drug and released almost all the drug within $5 \mathrm{~min}$. The improved formulation could offer improved drug delivery for lurasidone hydrochloride after establishing the pharmacokinetic studies of improved formulation.

\section{ACKNOWLEDGMENTS}

The authors are thankful to Torrent Pharmaceuticals, Cadila Pharmaceuticals Limited, Ahmedabad, International Specialty Products, Singapore., ACS chemicals, Ahmedabad., Loba chemie, Mumbai., Finar Limited, Ahmedabad.

\section{REFERENCES}

1. Frye MA, Prieto ML, Bobo WV, Kung S, Veldic M, Alarcon RD, et al. Current landscape, unmet needs, and future directions for treatment of bipolar depression. J Affect Disord. 2014;169 Suppl 1:S17-23. doi:10.1016/s0165-0327(14)70005-9.

2. Findlay LJ, El-Mallakh P, El-Mallakh RS. Management of bipolar I depression: clinical utility of lurasidone. Ther Clin Risk Manag. 2015;11:75-81. doi:10.2147/tcrm.s57695.

3. Ketter TA, Wang PW, Miller S. Bipolar therapeutics update 2014: a tale of 3 treatments. J Clin Psychiatry. 2015;76(1):69-70. doi:10.4088/JCP.14ac09649. 
4. Bahk W-M, Woo YS, Wang HR. Lurasidone as a potential therapy for bipolar disorder. Neuropsychiatr Dis Treat. 2013;9:15219. doi:10.2147/ndt.s51910.

5. Ishibashi $\mathrm{T}$, Horisawa $\mathrm{T}$, Tokuda $\mathrm{K}$, Ishiyama $\mathrm{T}$, Ogasa $\mathrm{M}$, Tagashira R, et al. Pharmacological profile of lurasidone, a novel antipsychotic agent with potent 5-hydroxytryptamine 7 (5-HT7) and 5-HT1A receptor activity. J Pharmacol Exp Ther. 2010;334(1):171-81. doi:10.1124/jpet.110.167346.

6. Bobo WV. Asenapine, iloperidone and lurasidone: critical appraisal of the most recently approved pharmacotherapies for schizophrenia in adults. Expert Rev Clin Pharmacol. 2013;6(1):61-91. doi:10.1586/ecp.12.70.

7. Bawa R, Scarff JR. Lurasidone: a new treatment option for bipolar depression—a review. Innov Clin Neurosci. 2015;12(12):21-3.

8. Latuda Prescribing Information accessed from http:// www.latuda.com/bpd/what-is-bipolar-depression.html. Accessed 15 Sept 2014.

9. Australian Public Assessment Report for lurasidone hydrochloride accessed from http://www.tga.gov.au/pdf/auspar/ausparlurasidone-hydrochloride-140620.pdf. Accessed 1 Oct 2014.

10. Christiansen ML, Holm R, Kristensen J, Kreilgaard M, Jacobsen $\mathrm{J}$, Abrahamsson B, et al. Cinnarizine food-effects in beagle dogs can be avoided by administration in a self nano emulsifying drug delivery system (SNEDDS). Eur J Pharm Sci. 2014;57:164-72. doi:10.1016/j.ejps.2013.11.003.

11. Kesisoglou F, Panmai S, Wu Y. Nanosizing-oral formulation development and biopharmaceutical evaluation. Adv Drug Deliv Rev. 2007;59:631-44.

12. Parthasaradhi RB, Rathnakar RK, Muralidhara RD, Srinivas RI, Subash CRK, Vamsi KB. Lurasidone hydrochloride solid dispersion. Google Patents. 2015.

13. Marom E, Rubnov S. Amorphous form of lurasidone hydrochloride. Google Patents. 2012.

14. Madan JR, Pawar KT, Dua K. Solubility enhancement studies on lurasidone hydrochloride using mixed hydrotropy. Int J Pharm Investig. 2015;5(2):114.

15. Qian S, Heng W, Wei Y, Zhang J, Gao Y. Coamorphous lurasidone hydrochloride-saccharin with charge-assisted hydrogen bonding interaction shows improved physical stability and enhanced dissolution with $\mathrm{pH}$-independent solubility behavior. Cryst Growth Des. 2015;15(6):2920-8. doi:10.1021/ acs.cgd.5b00349.

16. Kesisoglou F, Panmai S, Wu Y. Application of nanoparticles in oral delivery of immediate release formulations. Curr Nanosci. 2007;3:183-90.

17. Pawar VK, Singh Y, Meher JG, Gupta S, Chourasia MK. Engineered nanocrystal technology: in-vivo fate, targeting and applications in drug delivery. J Control Release. 2014;183:51-66. doi:10.1016/j.jconrel.2014.03.030.
18. Leone F, Cavalli R. Drug nanosuspensions: a ZIP tool between traditional and innovative pharmaceutical formulations. Expert Opin Drug Deliv. 2015;1-19. doi:10.1517/17425247.2015.1043886.

19. Kwok PC, Chan HK. Nanotechnology versus other techniques in improving drug dissolution. Curr Pharm Des. 2014;20(3):474-82.

20. Gao L, Liu G, Ma J, Wang X, Zhou L, Li X. Drug nanocrystals: in vivo performances. J Control Release. 2012;160:418-30.

21. Shah SR, Parikh RH, Chavda JR, Sheth NR. Glibenclamide nanocrystals for bioavailability enhancement: formulation design, process optimization, and pharmacodynamic evaluation. J Pharm Innov. 2014;9(3):227-37.

22. Shah SR, Parikh RH, Chavda JR, Sheth NR. Application of Plackett-Burman screening design for preparing glibenclamide nanoparticles for dissolution enhancement. Powder Technol. 2013;235:405-11. doi:10.1016/j.powtec.2012.10.055.

23. United States Food and Drug Administration Guidelines for dissolution testing of Latuda http://www.accessdata.fda.gov/ drugsatfda_docs/appletter/2010/200603s000ltr.pdf. Accessed 5 Oct 2014.

24. United States Food and Drug Administration guidelines for dissolution testing of lurasidone hydrochloride accessed from http:// www. accessdata.fda.gov/scripts/cder/dissolution/ dsp_SearchResults_Dissolutions.cfm?PrintAll=1. 15 Sept 2014.

25. Shah SR, Patel R, Soniwala M, Chavda JR. Development and optimization of press coated tablets of release engineered valsartan for pulsatile delivery. Drug Dev Ind Pharm. 2015;Early Online:1-12.

26. Ghosh I, Schenck D, Bose S, Ruegger C. Optimization of formulation and process parameters for the production of nanosuspension by wet media milling technique: effect of vitamin E TPGS and nanocrystal particle size on oral absorption. Eur J Pharm Sci. 2012;47(4):718-28. doi:10.1016/j.ejps.2012.08.011.

27. Liu Y, Chen ZQ, Zhang X, Feng NP, Zhao JH, Wu S, et al. An improved formulation screening and optimization method applied to the development of a self-microemulsifying drug delivery system. Chem Pharm Bull. 2010;58(1).

28. Verma S, Lan Y, Gokhale R, Burgess DJ. Quality by design approach to understand the process of nanosuspension preparation. Int J Pharm. 2009;377(1):185-98.

29. Gao L, Zhang D, Chen M. Drug nanocrystals for the formulation of poorly soluble drugs and its application as a potential drug delivery system. J Nanoparticle Res. 2008;10(5):845-62. doi:10.1007/s11051-008-9357-4.

30. Gohel MC, Parikh RK, Aghara PY, Nagori SA, Delvadia RR, Dabhi MR. Application of simplex lattice design and desirability function for the formulation development of mouth dissolving film of salbutamol sulphate. Curr Drug Deliv. 2009;6:486-94.

31. Liu Y, Chen Z, Zhang X, Feng N, Zhao J, Wu S, et al. An improved formulation screening and optimization method applied to the development of a self-microemulsifying drug delivery system. Chem Pharm Bull (Tokyo). 2010;58(1):16-22. 